* Graduando em Direito pela Universidade Estadual Vale do Acaraú (UVA). Integrante da Linha de Pesquisa Direito, Regulação e Desenvolvimento.Email: jaksonrocha7@ hotmail.com.

* Pós-Doutora em Direito pela Universidade Federal de Santa Catarina (UFSC). Doutora em Direito Constitucional pela Universidade de Fortaleza (UNIFOR). Mestre em Direito e Desenvolvimento pela Universidade Federal do Ceará (UFCE). Graduada em Direito pela Universidade Federal do Ceará (UFCE). Professora da Faculdade UNICHRISTUS. Professora Adjunta da Universidade Estadual Vale do Acaraú (UVA). Coordenadora do Curso de Direito da Faculdade Luciano Feijão (FLF). Líder do Grupo de Pesquisa Direito, Regulação e Desenvolvimento. Email: realbuquerque@ yahoo.com.

\section{Atos de Concentração Econômica \\ E Estruturas de Mercado em uma \\ Concorrência Praticável}

\author{
ACTS OF ECONOMIC CONCENTRATION AND \\ Market Structures in a Workable \\ COMPETITION
}

\begin{abstract}
Jackson Lima Rocha*
Renata Albuquerque Lima**

Lívya Maria Vaz Cordeiro***
\end{abstract}

Como citar: ROCHA, Jackson Lima; LIMA, Renata Albuquerque; CORDEIRO, Lívya Maria Vaz. Atos de concentração econômica e estruturas de mercado em uma concorrência praticável. Scientia Iuris, Londrina, v. 21, n. 2, p.64-97, jul. 2017. DOI: $10.5433 / 2178-8189.2017 \mathrm{v} 21 \mathrm{n} 1 \mathrm{p} 64$. ISSN: $2178-8189$.

Resumo: O presente artigo trata dos atos de concentração econômica em um contexto de análise das estruturas de mercado e a forma como estas auxiliam nos estudos sobre as características da concorrência praticável. Baseando-se em uma exposição didática, os autores analisam o Sistema Brasileiro de Defesa da Concorrência, o Conselho Administrativo de Defesa Econômica e dispositivos legais que são essenciais para o assunto. Trata-se, também, das diferenças entre as concorrências perfeita e praticável, das estruturas de mercado, sob a ótica do mercado relevante, bem como 
das principais formas de concentração que ocorrem entre as empresas que exploram a economia.

Palavras-chave: A tos de concentração econômica. Concorrência praticável. Estruturas de mercado.

Abstract: This paper analyzes 'acts of economic concentration' with the use of a market structure analysis, and explores the mode in which they assist research-based studies that examine the characteristics of fair competition. Moreover, with the use of a clear didactic exposition, these authors analyze the Brazilian Competition Defense System, the Administrative Council for Economic Defense, and specific norms that are of absolute importance to this subject matter. This study also differentiates 'perfect competition' from 'workable competition'; investigates market structures through relevant markets; and explores the many forms of concentration that occur between companies.

Keywords: Acts of economic concentration. Workable competition. Market structures.
* Graduanda em Direito pela Universidade Estadual Vale do Acaraú (UVA). Monitora da Disciplina de Hermenêutica Jurídica na Universidade Estadual Vale do Acaraú (UVA). Integrante da Linha de Pesquisa Direito, Regulação e Desenvolvimento. Email:1ivvaz95@gmail.com. 


\section{INTRODUÇÃO}

Diversos atos praticados pelas empresas que diariamente disputam em um mercado competitivo têm a potencialidade para causar alterações de cunho estrutural que variam de acordo com a intensidade em que se dão, podendo melhorar a quantidade ou a qualidade do produto ou serviço ofertados, mas também vindo a promover, direta ou indiretamente, o desenvolvimento de barreiras para a entrada de novas empresas que venham a explorar a atividade econômica, bem como o aumento dos preços e, consequentemente, o estabelecimento de um intenso poder econômico diante do ramo em que atuam.

Este tão almejado poder, atributo que se apresenta das mais variadas formas, pode trazer benefícios e malefícios à economia, o que a curto ou longo prazo pode ser notado pelos agentes que movimentam o mercado, e entre estes, os próprios consumidores.

Diante desses atos que ocorrem nas mais complexas e variadas situações e condições, em meio a uma sociedade que se amplia e a cada dia se depara com novas técnicas e influências advindas do processo de globalização, acentuando-se na expansão de empresas até mesmo a níveis intercontinentais, deve-se haver uma maior cautela no que diz respeito à fiscalização e suporte legais, por meio das normas editadas pelo Poder Legislativo, com vistas a inovar o conjunto normativo que regula a defesa da concorrência, e, mais especificamente, os atos e contratos que se desenrolam mediante o fenômeno da concentração. Tal operação, portanto, deve ser feita de maneira eficaz, visando a colocação na prática dessas leis, de um modo que os resultados sejam evidentes para os agentes econômicos.

Dessa forma, objetiva-se nessa investigação a feitura de um 
exame dos atos de concentração econômica que tenham a capacidade de alterar as estruturas competitivas presentes na economia atual, no que concerne às suas características, fatos históricos e institutos auxiliares para a melhor compreensão do tema.

A argumentação é baseada nas normas existentes no ordenamento jurídico do Brasil, bem como nos estudos desenvolvidos pelos pesquisadores dessa área que se desenvolve constantemente, exigindo elevado grau de observação por parte da doutrina e órgãos responsáveis pela consecução das normas de defesa da concorrência e apreciação das práticas empresariais que afetam economia em seus mais diversos setores e especificidades.

Através disso, verifica-se ainda a importância de tratar das finalidades que justificam a proteção constitucional da livre concorrência, pois tais objetivos envolvem valores de natureza pública e essenciais à manutenção da ordem e segurança jurídica na sociedade.

Dá-se particular relevância à concorrência praticável, ou workable competition, como se verá no decorrer do estudo, uma vez que esta molda e atualiza as tradicionais concepções das estruturas de mercado.

Realiza-se, também, uma abordagem dos tópicos relacionados ao mercado relevante, com atenção especial à Resolução nº 49 do Cade, e às estruturas de mercado existentes para compreender os espaços físico e jurídico nos quais acontecem o fenômeno concentracionista e finalizando com uma amostra explicativa das principais formas de concentração que geralmente ocorrem no cotidiano das atividades empresarial e econômica em geral.

Salienta-se que o estudo, sempre que necessário, dará ênfase à atuação dos agentes em face dos benefícios que eles venham a trazer 
à sociedade e às pessoas individualmente consideradas, visto que os cidadãos devem ser respeitados e ter prioridade nas apreciações feitas pelos órgãos de defesa da concorrência e, principalmente, na própria formação de acordos e nas práticas econômicas. A dignidade da pessoa humana, como fundamento da República Federativa do Brasil de acordo com a Constituição de 1988, deve orientar também os estudos, atos e opiniões econômicas, e é isso que se busca na presente investigação (BRASIL, 1988).

\section{NOÇÕES DE DEFESA DA CONCORRÊNCIA NO ORDENAMENTO JURÍDICO BRASILEIRO}

A legislação brasileira dispõe de diversas normas que versam sobre aspectos relacionados à defesa da concorrência, e consequentemente, ao controle dos atos de concentração. A própria Constituição da República Federativa do Brasil, promulgada no ano de 1988, em seu texto de importância ímpar ao estudo aqui proposto, dispõe sobre o tema, dentre outros dispositivos, no $\S 4^{\circ}$ do seu Art. 173, da seguinte maneira: "lei reprimirá o abuso do poder econômico que vise à dominação dos mercados, à eliminação da concorrência e ao aumento arbitrário dos lucros".

Acerca da atuação estatal no sentido de efetivar os pressupostos constitucionais, sob a ótica do Estado regulador e dos importantes direitos fundamentais, Lima (2014, p. 34) afirma:

A Constituição Federal de 1988, no que respeita, principalmente, aos Arts. $1^{\circ}, 3^{\circ}, 5^{\circ}$, inciso XXIII, e 170, inciso III, confere outra finalidade ao exercício da atividade econômica, qual seja o atendimento, 
em paralelo ao lucro, dos direitos e garantias fundamentais, bem como fundamentos e objetivos da República Federativa do Brasil. Trata-se da verificação da dimensão socioeconômica da iniciativa privada, bem como de sua capacidade de promoção do bem-estar social, ou seja, é a reversão da obtenção dos proveitos para também beneficiar a coletividade, seja no investimento em infraestrutura, modernização e universalização do serviço público, diminuição das desigualdades, etc.

Sendo assim, é com base no texto constitucional que opera o Sistema Brasileiro de Defesa da Concorrência, o SBDC, que, de acordo com o Art. $3^{\circ}$ da Lei $n^{o} 12.529$ de 2011, é formado pelo Conselho Administrativo de Defesa Econômica (o Cade) e pela Secretaria de Acompanhamento Econômico do Ministério da Fazenda (BRASIL, 2011). Tal norma ainda afirma que o Conselho e a Secretaria abordados possuem as atribuições trazidas nesta Lei, a qual, dentre outras providências, estrutura o Sistema Brasileiro de Defesa da Concorrência e dispõe sobre a prevenção e repressão às infrações contra a ordem econômica.

Ademais, é válido ressaltar o fato de que a Lei no 12.529/2011 revogou os dispositivos da conhecida Lei no 8.884/1994 (BRASIL, 1994), muito marcante no desenvolvimento da legislação antitruste no Brasil e que, dentre outras providências, transformou o Cade em autarquia.

Para o estudo que aqui se pretende trazer, todavia, faz-se necessário, de per si, uma abordagem mais minuciosa do trabalho desempenhado pelo Cade, visto que a este é designado a função da apreciação dos atos de concentração. Da Lei n 12.529/2011 pode-se, ainda, obter o conceito legislativo do Cade, pois do seu Art. $4^{\circ}$ tem-se que é a "entidade judicante com jurisdição em todo o território nacional, 
que se constitui em autarquia federal, vinculada ao Ministério da Justiça, com sede e foro no Distrito Federal, e competências previstas nesta Lei”. Porém, após a leitura da Lei, para evitar comparações equivocadas no que diz respeito à atuação do Cade no Brasil, é preciso pontuar as sábias palavras de Masso (2013, p. 166), segundo o qual:

O Cade na condição de autarquia não realiza função jurisdicional, é bom lembrar que o nosso sistema não é o francês. Quando lemos "jurisdição" devemos pensar em aplicação administrativa da legislação contra o abuso do poder econômico, o que não veda a apreciação judicial quando for o caso. O Sistema Brasileiro de Defesa da Concorrência representa de forma bem clara a atuação indireta do Estado no domínio econômico. Diante da leitura das competências dos vários órgãos criados, é patente o controle do mercado pelo Estado, ou seja, não vale o argumento de que por não corresponder a regulação de um mercado específico e sim da concorrência que descaracteriza o Sistema como um instrumento indireto do Estado para regular o mercado.

Dadas essas informações basilares, observa-se que quando duas ou mais empresas pretendem unir forças e realizar um ato que pode ser caracterizado como concentracionista, elas precisam, antes de consumar o ato oficialmente, da permissão do Conselho Administrativo de Defesa Econômica. O Cade vai apreciar o ato ou contrato baseando-se nos potenciais efeitos que venham a ser produzidos mediante o mercado a ser considerado. Essa análise é de extrema importância, pois é assim que se verificam os benefícios e os malefícios que daí possam surgir.

A legislação antitruste não estabelece um rol de determinados atos de concentração que necessariamente são considerados ilícitos 
ou causadores de prejuízos à concorrência. Não é assim que o sistema funciona. $\mathrm{O}$ trabalho é feito a partir da averiguação de cada caso, em determinadas circunstâncias e naquele determinado momento em que se encontra a economia.

Portanto, mesmo que aquele ato venha a causar prejuízos à concorrência, se os benefícios à população forem maiores naquela determinada situação, por exemplo, poderá haver a convalidação ou aceitação da concentração. É este o disposto na Lei no ${ }^{\circ} 12.529 / 2011$, partindo-se de uma interpretação teleológica, como se pode observar nos $\S \S 5^{\circ}$ e $6^{\circ}$ do Art. 88 , situado no Título VII da Lei, que dispõe acerca "Do Controle das Concentrações":

§ 5 Serão proibidos os atos de concentração que impliquem eliminação da concorrência em parte substancial de mercado relevante, que possam criar ou reforçar uma posição dominante ou que possam resultar na dominação de mercado relevante de bens ou serviços, ressalvado o disposto no $\S 6^{\circ}$ deste artigo. $\S 6^{\circ}$ Os atos a que se refere o $\S$ 5o deste artigo poderão ser autorizados, desde que sejam observados os limites estritamente necessários para atingir os seguintes objetivos:

I - cumulada ou alternativamente:

a) aumentar a produtividade ou a competitividade;

b) melhorar a qualidade de bens ou serviços; ou

c) propiciar a eficiência e o desenvolvimento tecnológico ou econômico; e

II - sejam repassados aos consumidores parte relevante dos benefícios decorrentes (BRASIL, 2011).

O trabalho de apreciação do Cade em face do ato de concentração o qual as empresas interessadas pretendem consumar é uma das formas 
de tratamento que objetiva a defesa da concorrência. A abordagem aqui se trata de uma regulação preventiva, que é a principal maneira de lidar com o fenômeno da concentração.

Essa submissão das empresas ao poder público é de suma importância, pois proporciona uma organização social, através da qual é possível trazer maiores benefícios aos cidadãos ou, pelo menos, para que se possa impedir o estabelecimento de problemas que afetam a população em geral, nos mais diversos aspectos cotidianos, seja na compra e venda de alimentos, roupas, bebidas ou serviços de lazer.

Um detalhe importante reside no fato de que quando o Conselho aprecia $\mathrm{o}$ ato, não há propriamente um julgamento no sentido formal $\mathrm{e}$ conhecido da palavra, isso pois não há a infração que precisa ser punida, bem como não se trata, ao menos inicialmente, de partes opostas que procuram o Poder Judiciário para a solução de uma lide. De fato, o que se tem são partes que têm a pretensão de concretizar um ato de concentração, e para isso, elas buscam o Cade para que este as autorize na feitura dos seus objetivos (JÚNIOR, 1996 apud MASSO, 2013, p. 203).

No entanto, em determinados casos, que não raro ocorrem na atividade empresarial, é possível notar que a concentração econômica já se deu no âmbito do mercado a ser considerado, provocando, ainda, efeitos prejudiciais ou mesmo devastadores às empresas que estão competindo. Sendo assim, a apreciação do Cade acerca do ato não se mostra mais tão útil, visto que as consequências se mostram ruins na prática.

Com isso, pontua-se a existência uma outra faceta do amparo à concorrência, por meio da repressão do ato, que deve ser feita com muito cuidado, devendo ser observados os direitos das partes, a apresentação de provas que delimitem a infração e a defesa das empresas para que a justiça 
seja plena. Aliás, esse poder não se manifesta de uma forma punitiva e visando unicamente o ius puniendi estatal, pois essa proteção se baseia na supremacia e indisponibilidade do interesse público, compondo um poder inibitório.

Ademais, caso o Cade não aprove a concentração que foi ao seu exame, ou ainda para que haja a repressão do ato que se formou, poderá ser determinado, dentre outras providências, que seja feita a desconstituição, buscando-se o retorno do status quo ante. Pode haver ainda a venda da marca ou dos ativos e paralisação total ou em parte das atividades.

Aliás, é recomendado que, na medida das possibilidades e circunstâncias presentes do caso concreto, tudo aconteça de forma célere, ou seja, a reposta deve ser rápida, por meio de procedimentos eficientes e pouco burocráticos, para que as empresas sofram menos incômodos, o que vem a proteger, direta ou indiretamente, os próprios consumidores que movimentam o mercado.

Por fim, antes de abordar o próximo tópico, é importante destacar os fins que são perseguidos pelo Direito da Concorrência, incluindo-se a legislação vigente sobre a matéria e a atuação dos órgãos que formam o Sistema Brasileiro de Defesa da Concorrência, o SBDC. Nesse sentido, pontua Macedo (2008, p. 39) citando Cunha (2003, p. 24), o qual argumenta que no trabalho desse arcabouço em prol da causa concorrencial:

Os fins gerais dividem-se em econômicos e não econômicos. O principal objetivo econômico para proteger a competição é o de maximizar a riqueza econômica do consumidor por meio do emprego de recursos escassos, e, mediante o progresso no 
desenvolvimento de novas técnicas produtivas e novos bens, atingir o melhor aproveitamento desses recursos. As duas espécies de fins gerais não se complementam obrigatoriamente, podendo ser excludentes no caso de colisão. Por exemplo, podem divergir no momento em que a eficiência dos agentes econômicos determine o desaparecimento de pequenas empresas em prol de grandes produtores, ou no instante em que as economias de escala na produção ou na distribuição reduzam o número de firmas produtoras ou distribuidoras. A escolha dos objetivos a serem perseguidos depende da análise política, que deve corresponder à realidade da região na qual a lei de defesa da concorrência deverá ser aplicada. A regulamentação e aplicação destas normas devem, então, conformar-se de forma a possibilitar a consecução dos fins estabelecidos.

\section{AS CONCEPÇÕES DE CONCORRÊNCIA PERFEITA E CONCORRÊNCIA PRATICÁVEL}

A manutenção de uma infinidade de empresas no mercado competitivo, explorando a economia das mais variadas formas e em seu clímax de atividades, trazendo todos os benefícios possíveis aos consumidores e sociedade em geral, gerando muito lucro, produzindo em grande escala e com preços baixos parecem ser o objetivo do Sistema Brasileiro de Defesa da Concorrência (SBDC), em uma visão de concorrência para início de discussão.

Entretanto, não há dificuldade em perceber que atingir esses níveis de perfeição concorrencial mostra-se claramente um desafio e os órgãos que regem a legislação antitruste no Brasil sabem dessa realidade, principalmente se forem levados em conta os números anuais 
da economia do país. Todavia, sabendo da relevância dos ideais do direito da concorrência e a necessidade da disputa no âmbito empresarial, sintetiza Forgioni (2009, p. 209) que:

[...] a disputaé, assim, essencial para o desenvolvimento das atividades empresariais e, apenas nessa medida, desejada pelo agente econômico. Em verdade, a empresa não aprecia a concorrência; suporta-a porque esta é a forma admissível de conquistar mercado e de aumentar os lucros. Pode-se então dizer que a disputa produz externalidade positiva, pois reverte a favor do funcionamento do sistema econômico, diminuindo preços e aumentando a qualidade do produto ou do serviço oferecido aos consumidores.

São muitos os benefícios do respeito à concorrência, como os citados por Forgioni acima, o que leva muitos estudiosos a aclamar a chamada concorrência perfeita, tão almejada pelas economias mundiais (pelo menos em seus respectivos ordenamentos jurídicos), a qual prega que devem ser mantidos algumas características que lhe são essenciais. Masso (2013, p. 211) elenca alguns desses pontos:

- Existe claramente um enorme número de agentes que movimentam a economia ativamente em ambos os polos, ou seja, na demanda e na oferta. Um detalhe importante para a concorrência perfeita reside no fato de que nenhum desses agentes pode, em sua unanimidade e individualidade, modificar consideravelmente o volume global da produção, muito menos os preços estabelecidos para os seus produtos ou ainda outro dado relevante;

- Também é evidente que os serviços e/ou produtos materiais que são ofertados por cada um dos sujeitos que agem nesse mercado são, ao menos substancialmente, tão semelhantes entre si, a 
ponto de os consumidores não terem preferência pela mercadoria de uma empresa sobre a mercadoria da mesma qualidade de outra empresa;

- Tanto os consumidores quanto os produtores tomam conhecimento de todos os acontecimentos que se dão na economia, causando, assim, uma publicidade cristalina e proporcionando a manifestação das opiniões dos agentes, os quais podem, baseados na ciência de todos os fatos, expressar seus devidos posicionamentos acerca do que consomem e vendem, sempre respeitando uns aos outros e mantendo a ordem no mercado;

- Inexistem dificuldades estratégicas para a chegada de novos agentes no mercado, visto que isso afrontaria a ordem e justiça estabelecidas, dando margem à ruptura da concorrência perfeita. Assim, novos sujeitos produtores adentram ao ambiente econômico com grande facilidade e mantêm-se com igualdade de condições, sendo todos beneficiados de igual forma. Ademais, os fatores de produção também saem de um setor de produção para outro, livre e facilmente.

Após a análise dessas principais características, é nítido que a aclamada concorrência perfeita só existe na teoria, como argumentam diversos estudiosos, não podendo ser visualizada na realidade das economias e mercados.

Até mesmo países que possuem uma estrutura econômica invejável têm um ou outro aspecto que exige uma melhoria ou deixam a desejar, principalmente no que diz respeito ao direito da concorrência e os atos de concentração.

Em uma reflexão mais aprofundada e teórica, poderia se afirmar que até mesmo o fenômeno da concentração econômica seria uma afronta à concorrência perfeita em seus ideais, pois atos concentracionistas implicam, por diversas vezes, na diminuição da concorrência ou na 
imposição do poder de mercado, mudando a situação de paridade entre as empresas.

Criticando os postulados da concorrência perfeita e, de modo didático para compreensão da realidade econômica, Varella Bruna (1997, p. 31) explica que:

No modelo de concorrência perfeita, o produtor é, por assim dizer, um escravo do mercado: incapaz de nele influir, mas por ele absolutamente controlado; forçado a produzir, em conjunto com seus concorrentes, tanto quanto seja possível, a fim de reduzir a escassez ao mínimo, segundo as possibilidades econômicas materiais existentes. Sua remuneração é a menor possível, o mínimo necessário para que ele se mantenha em atividade. Ganancioso, porque procura elevar seu lucro ao máximo, é uma fera enjaulada, enclausurada pelas barreiras intransponíveis impostas inexoravelmente pelo mercado.

Dado isso, atualmente tem-se como entendimento doutrinário mais aceito o de que a concorrência que se pretende manter é a chamada de praticável, mundialmente conhecida pela expressão "workable competition", advinda dos importantes estudos desenvolvidos pela Escola Estruturalista de Harvard (DAL RI JUNIOR; LIMA, 2016). É com essa ideia de concorrência que se busca a manutenção de um número suficientemente bom de empresas ou ofertantes, para que os consumidores tenham razoável poder de escolha sobre os produtos disponíveis.

Além disso, levam-se em consideração os fatos verídicos que acontecem no mercado econômico, como preços estabelecidos por cada empresa, diversificação dos produtos e serviços ofertados por cada um dos agentes, publicidade moderada e atos de concentrações frequentemente 
feitos entre aliados em ação.

Por isso, Forgioni (2005, p. 168-170) se posiciona na defesa da workable competition, sabendo que o excesso de atos potencialmente prejudiciais ao mercado deve ser evitado, porém reconhecendo que práticas as quais são capazes de gerar efeitos negativos na atividade empresarial geralmente estão presentes, ao afirmar:

Em linhas gerais, a Escola de Harvard sustenta que devem ser evitadas as excessivas concentrações de poder no mercado, que acabam por gerar disfunções prejudiciais ao próprio fluxo das relações econômicas, buscando-se um modelo de workable competition. Essa questão, por sua vez, está relacionada com o problema do número de agentes econômicos atuantes em determinado setor da economia. O modelo de concorrência que se propugna implica a manutenção ou incremento do número de agentes econômicos no mercado, sendo a concorrência buscada como um fim em si mesma. Dessa forma, mantém-se a estrutura pulverizada, evitando-se as disfunções no mercado.

Também ao abordar uma compreensão realista, considerando o fator dos lucros e benefícios advindos com uma melhoria na eficiência empresarial, bem como o aspecto social do estudo, Nusdeo (2002, p. 48) acata os atuais posicionamentos sobre o teor da concorrência praticável e orienta aos órgãos responsáveis pela defesa da concorrência que é necessário, quando estiverem diante de determinado ato de concentração o qual tenha-se mostrado positivo para o aumento da eficiência da empresa, que essa autoridade antitruste analise a proporcionalidade entre o meio escolhido e o os fins desejados, bem como se não poderia ser escolhida uma alternativa menos lesiva à economia, se uma grande eliminação 
da concorrência não resultará do ato constituído e, especialmente, se a sociedade poderá desfrutar dos benefícios daí advindos.

\section{O MERCADO RELEVANTE E AS ESTRUTURAS DE MERCADO}

Saber identificar a qual mercado relevante determinada empresa pertence é essencial para que se possa mensurar os impactos que esse agente pode causar nas estruturas competitivas e o que pode resultar se certos sujeitos econômicos praticarem um ato de concentração. Além disso, o conceito de mercado relevante auxilia no entendimento das estruturas de mercado.

De forma simples, diz-se que o mercado relevante é aquele espaço que deve ser levado em consideração quando da atuação de um agente na economia. Se o comportamento de uma empresa influencia ou reflete no estabelecimento de preços ou na quantidade de produção de outra empresa, verifica-se que elas pertencem ao mesmo mercado relevante (CREMA, 2010, p. 41). Pode-se também levar em consideração o conceito trazido pela Resolução $n^{\circ} 49$ do Cade, segundo o qual o:

"Mercado Relevante" é aquele mercado determinado em termos de produtos e área geográfica no qual é possível o exercício do poder de mercado. Segundo o teste do "monopolista hipotético", o mercado relevante é definido como o menor grupo de produtos e a menor área geográfica necessários para que um suposto monopolista esteja em condições de impor um "pequeno porém significativo e não transitório" aumento de preços (CADE, 2008, p. 3).

Sendo assim, o mercado relevante deve ser entendido pela 
complementação de dois aspectos necessários, os quais são trazidos a seguir.

Primeiramente, tem-se Mercado Relevante Material ou do Produto, que se dá pela perspectiva do consumidor, ou seja, se este pode trocar um determinado produto, por exemplo, por outro que lhe seja substancialmente semelhante, pode-se afirmar que estas mercadorias pertencem ao mesmo mercado relevante material. É nesse sentido que afirma a Resolução n 49 do Cade (2008, p. 3), segundo a qual tal mercado "compreende todos os bens/serviços considerados substituíveis entre si pelo consumidor ou usuário devido às suas características, preços e utilização." A Resolução também sintetiza que o Mercado Relevante do Produto pode, ainda, ter em sua composição um determinado número de serviços ou bens que venham a apresentar algumas características físicas, técnicas ou de comercialização que recomendem o agrupamento (BRASIL, 2008).

Por outro lado, o Mercado Relevante Territorial ou Geográfico diz respeito justamente ao plano físico do mercado, que pode abranger estados, regiões, países e até mesmo continentes, como se pode verificar com o processo de globalização. De acordo com a Resolução n 49 do Cade, tem-se que:

"Mercado Relevante Geográfico" compreende a área em que as empresas ofertam e procuram produtos (bens ou serviços) em condições de concorrência suficientemente homogêneas em termos de preços, preferências dos consumidores, características dos produtos. A definição de um mercado relevante geográfico exige também a identificação dos obstáculos à entrada de produtos ofertados por firmas situadas fora dessa área. As firmas capazes 
de iniciar a oferta de produtos na área considerada após uma pequena mas substancial elevação dos preços praticados fazem parte do mercado relevante geográfico. Nesse mesmo sentido, fazem parte de um mercado relevante geográfico, de um modo geral, todas as firmas levadas em conta por ofertantes e demandantes nas negociações para a fixação dos preços e demais condições comerciais na área considerada (CADE, 2008, p. 3).

Compreendidos o conceito e facetas do mercado relevante, agora é necessária a análise das estruturas de mercado. Tais estruturas, em sua ideia tradicional, eram compreendidas simplesmente pelo número e tamanho das firmas presentes em um mercado relevante. Porém, devido à especificação e complexidade das situações que começaram a aparecer e precisavam de um suporte jurídico, adota-se, atualmente, um conceito mais dinâmico, que engloba diversos fatores. Tais fatores serão verificados com o exame didático e breve das estruturas de mercado básicas, que são a seguir descritas.

Os Mercados de Concorrência Perfeita são aqueles mercados que atendem a todas as características formadoras da concorrência perfeita, como já foi explicado e detalhado no presente trabalho. Ressaltase que, na prática, essa estrutura de mercado dificilmente ou nunca será encontrada, visto que até mesmo as economias invejáveis de países desenvolvidos tendem a apresentar aspectos que exigem melhorias ou reformas estruturais.

É comum também falar-se nos Mercados de Concorrência Monopolista. Nestes, uma grande quantidade de agentes econômicos está em ação, competindo, porém, existe diferença bastante acentuada entre seus produtos, e por isso são necessários investimentos em publicidade 
para que os consumidores tomem consciência das distinções e comprem o que lhes aprouver (MASSO, 2013, p. 215). Essa estrutura de mercado é normalmente tratada como a zona intermediária entre o monopólio e a concorrência perfeita.

Já os Monopólios são bastante discutidos e polêmicos no âmbito da doutrina jurídica e econômica em geral. Ao contrário dos mercados de concorrência perfeita, caracterizam-se por serem estruturas de mercado nas quais apenas um agente detém o controle no que diz respeito à oferta de uma mercadoria, produto ou serviço. Além disso, é possível notar que não se encontra no mercado nenhum produto que tenha a capacidade de efetivamente substituir a produção do agente monopolista, até mesmo pelo fato de não haver competidores imediatos. Assim, os juristas são enfáticos nesse aspecto, adotando geralmente um pensamento uniformizado com relação ao conceito e abordagens dos monopólios:

O conceito de monopólio é de caráter eminentemente econômico, traduzindo-se no poder de atuar em um mercado como único agente econômico [...] Monopólio é a exploração exclusiva de determinada atividade econômica por um único agente, não se admitindo a entrada de novos competidores. Outrossim, por atividade econômica entende-se todo o processo de produção e circulação de bens, serviços e riquezas na sociedade (FIGUEIREDO, 2009, p. 11).

Nesse diapasão, é comum que grande parte dos estudiosos tenham a visão de que essa estrutura de mercado seja ruim, levando em consideração suas características e prejuízos à concorrência. Todavia, é válido notar que, dependendo da situação, os benefícios à sociedade podem se sobressair, visto que pode haver grande uso de tecnologia e 
formação de preços mais acessíveis. Nesses casos, a autoridade antitruste deverá ponderar sua análise para atender ao bem-estar social.

Tem-se ainda, os Oligopólios. Nessas espécies de estrutura de mercado encontra-se uma semelhança com os monopólios, todavia, enquanto nestes apenas um determinado agente econômico controla a oferta do setor, naqueles existe a presença de um pequeno número de agentes, ou seja, algumas empresas dominam o mercado. Nos oligopólios os produtos podem seguir um padrão ou não entre seus agentes, os quais, com frequência, realizam diversos acordos. Assim, devido ao poder econômico que esse grupo adquire, pode haver acentuada dificuldade para a entrada de novas empresas para competir no mercado. Miranda (2011), dado isso, sintetiza:

Oligopólio é uma situação de mercado nos países capitalistas onde existem poucos e grandes produtores de certa mercadoria ou serviço. O oligopólio se forma principalmente nas atividades econômicas que exigem grandes investimentos, ou aplicações de dinheiro. É o caso, por exemplo, do setor automobilístico. Outras atividades ou setores onde se verifica o oligopólio são: indústrias de lâmpadas elétricas, de lâminas de barbear, de cimento, de cigarros, etc.

A mesma observação feita aos monopólios deve ser feita ao versar sobre os oligopólios. Ou seja, com a produção de benefícios sociais resultantes da atividade econômica das empresas que constituem a estrutura de mercado, a visão negativa deve ser relativizada, até mesmo seguindo os ditames da Lei $n^{\circ} 12.529 / 2011$, a qual estrutura o Sistema Brasileiro de Defesa da Concorrência, como já abordado acima no presente paper. 
Para complementar a investigação, é interessante analisar a experiência norte-americana com os atos de concentração e estruturas de mercado usualmente tidas como lesivas à concorrência (monopólios e oligopólios, por exemplo).

O Sherman Act, importante documento para o direito da concorrência nos EUA, apresentava-se bem ríspido no que concerne ao tratamento da concentração econômica entre empresas, buscando sempre reprimir o abuso do poder econômico, e que, inicialmente, passou a usar desse objetivo sem ponderar os aspectos de cada situação. Tal fato pode ser analisado sob o ponto de vista histórico, uma vez que de acordo com Macedo (2008, p. 42-43):

No final do século XIX alguns fatores que influenciavam o perfil sócio-econômico da sociedade norte-americana foram determinantes para o surgimento da necessidade de se proteger a concorrência e para o surgimento do Sherman Act. Dentre esses fatores, destacam-se o fortalecimento e a concentração industrial, sobretudo no norte dos Estados Unidos, reflexo dos esforços bélicos empreendidos no período de guerra civil. Nesse mesmo período, a economia estadosunidense passava por um período de rápida transformação. De uma economia baseada na pequena empresa e no espírito empresarial individual, os Estados Unidos, após a guerra, tornavam-se uma economia demandante de uma maior concentração de capitais com vistas à produção em massa. Em vigorosa expansão industrial evidentemente, limitava o número de participantes no mercado, ao passo que estimulava as práticas desleais entre concorrentes, com consequências negativas para os consumidores. 
Assim, devido aos fatores da época, medidas eficazes tinham de ser tomadas para a proteção da concorrência, o que causou a aplicação generalizada do Sherman Act. Entretanto, tempos depois, a Suprema Corte Americana, mediante hermenêutica atualizada com interpretação teleológica, propõe a "Regra da Razão" (Rule of Reason), que prega a análise do caso concreto antes de dizer que determinado ato de concentração é necessariamente ilícito (MASSO, 2013, p. 218). Assim, a sua compreensão correta permite afirmar que:

Desde a promulgação do Sherman Act, o Direito da Concorrência nos Estados Unidos tem se enquadrado como mecanismo garantidor do sistema econômico, bem como uma garantia fundamental do cidadão na ordem econômica. A preocupação fundamental dessas garantias consiste no equilíbrio das relações econômicas proporcionado pelo Direito da Concorrência [...] (MACEDO, 2008, p. 43).

Tal análise pode ter influenciado a legislação brasileira no tratamento do fenômeno da concentração no Brasil, fazendo com que a experiência norte-americana seja exemplo de interpretação e aplicação legais para a defesa econômica e o tratamento dos atos de concentração.

\section{FORMAS MAIS COMUNS DOS ATOS DE CONCENTRAÇÃO}

No que tange às formas em que se dão as práticas de concentração econômica, deve-se observar, primeiramente, a classificação sob o ponto de vista da associação realizada. Dessa forma, os atos de concentração podem ser verticais, que são aqueles que ocorrem entre empresa, fornecedor e distribuidor ou entre outros agentes formando uma cadeia 
produtiva até chegar ao consumidor.

Há também as concentrações horizontais, que se caracterizam quando é realizada entre concorrentes que atuam em um mesmo mercado relevante. Nota-se que dos atos de concentração horizontais resultam os mais altos prejuízos. É nesse sentido que versa Macedo (2008, p. 35), ao tratar do assunto de forma eficiente

Tradicionalmente, as concentrações econômicas são classificadas entre horizontais e verticais. A primeira delas se processa entre os concorrentes em um mesmo mercado. Referidas concentrações podem representar uma ameaça à ordem econômica. A apreciação de tais atos se resume, via de regra, a determinar o nível de concentração a partir do qual é necessário o controle. A segunda se processa entre empresas que operam em diferentes níveis ou estágios de uma mesma atividade econômica, mantendo entre si relações comerciais. A implementação da política antitruste consiste basicamente em desestimular e coibir comportamentos ou práticas anticompetitivas, sejam elas de natureza vertical ou horizontal, por parte de empresas que detêm o poder de mercado, ou seja, que são capazes, por suas ações, de gerar situações em que a concorrência é restringida. Trata-se, portanto, de evitar, por meio da ameaça de punição, as condutas empresariais que visem inibir a ação dos concorrentes de limitar o alcance da competição por intermédio de algum tipo de colusão e/ou impor aos compradores (vendedores) condições desfavoráveis na aquisição de produtos. Práticas restritivas verticais são aquelas que limitam o escopo das ações de agentes que se relacionam como compradores e vendedores ao longo da cadeia produtiva ou nos mercados finais, incluindo condutas como a fixação de preços de revenda, as restrições territoriais e de bases de clientes, os 
acordos de exclusividade, a recusa da negociação, a venda casada e a discriminação de preços.

Ainda existem as concentrações conglomeradas, que acontecem quando empresas se unem atuando em mercados relevantes diferentes e não se relacionando da forma vertical (CREMA, 2010, p. 37-38).

Já com relação às próprias empresas que se unem, os atos de concentração recebem algumas denominações especiais e bastante conhecidas pelos estudiosos. A seguir serão tratadas algumas das principais formas de concentração que nesse acontecem âmbito.

Inicialmente, analisam-se os Trustes. Estes são formas de concentração de empresas que merecem bastante atenção nos estudos jurídicos e econômicos. Segundo Rudge (2003, p. 324) um truste é uma "combinação entre empresas para assegurar controle econômico sobre determinados mercados, a fim de afastar eventuais concorrentes e administrar os preços de vendas de seus produtos, em busca de lucros elevados". É, assim, um modo de direcionar para um rumo comum a ordem controladora de duas ou mais empresas, fazendo com que estas deixem suas independências jurídicas para formar um só agente. Ademais, sabe-se que, para que seja caracterizado como ilícito, o truste deverá ter uma prática comprovadamente ilícita, como por exemplo a redução excessiva da concorrência ou a exploração injusta dos consumidores.

Por outro lado, também devem ser mencionados os Cartéis. A principal característica dos cartéis é o fato de que eles se desenvolvem por meio de atos clandestinos, através dos quais um grupo de entes empresariais atuam de modo conjunto, mas não propriamente unidos, buscando a dominação do mercado ao impor preços equivalentes, utilizando de estratégias cuidadosamente pensadas e postas em prática 
para alcançar benefícios que não poderiam ser obtidos de forma mais fácil de outra maneira. Dessa forma, a doutrina geralmente define Cartel, além de realizar as necessárias observações:

[...] como uma política de preços, cujas regras são ditadas por uma ou mais sociedades que tenham domínio suficiente do mercado, o que significa dizer que se podem manter e, além do mais, estão em condições de obrigar as demais sociedades, sob pena de as mesmas serem "naturalmente" excluidas do mercado. Porém, nem sempre foi assim. Isabel Vaz ensina que, em alguns locais e épocas, as sociedades passaram a se associar com outras do mesmo nível na defesa contra o aviltamento dos preços em horas de crises agudas ou para subtraírem a concorrência danosa, aumentando, assim, seus lucros. Dessa prática é que depois surgiu o cartel, com um caráter pejorativo, significando o acordo entre sociedades para disciplinar a concorrência, por várias formas, evoluindo, em muitos casos, para a própria defesa econômica das empresas (atividade) símiles, por meio da constituição de órgãos centralizadores incumbidos da aquisição de matérias-primas, ou da venda dos produtos, ou da distribuição territorial das zonas de atuação (BORGES et al., 2002, p. 236, grifo do autor).

Já com relação às Joint ventures, deve-se atentar, primeiramente, ao simples fato de que expressão "joint venture" é proveniente da língua inglesa e é traduzida para o português como "empreendimento conjunto". Todavia, a versão no inglês é a mais usada nos livros que tratam da temática e também já é predominante no vocabulário econômico. Para entender detalhadamente essa espécie de ato de concentração, Miranda e Maluf (2016, p. 1) explicam: 
Joint Venture [...] corresponde a uma forma ou método de cooperação entre empresas independentes, denominado em outros países de sociedade entre sociedades, filial comum, associação de empresas, etc. A característica essencial do contrato de Joint Venture é a realização de um projeto comum, empreendimento cuja duração pode ser curta ou longa, porém com prazo determinado. É a celebração de um contrato entre duas ou mais empresas, que se associam, criando ou não uma nova empresa para realizar uma atividade econômica produtiva ou de serviços, com fins lucrativos. Uma Joint Venture pode ser criada para desenvolver uma série de atividades, tais como, projetos industriais, execução de obras, pesquisas e desenvolvimentos, atividades financeiras, prestação de serviços, etc. Cada parte que compõe os polos dessas associações deve trazer aquilo que possui de melhor, além disso, a transparência é essencial, pois a Joint Venture é a confiança entre as partes.

Essa forma de união de empresas é muito comum na atualidade, visto que os agentes econômicos continuam independentes juridicamente, além de serem bem simples em sua constituição e finalidade, as quais basicamente resumem-se em uma espécie de consórcio com vistas à realização de uma determinada atividade em comum para fomentar a economia e gerar lucros para os envolvidos.

Por último e não menos importante, existem as Holdings, que são formas de concentração muito conhecidas na atualidade e caracterizamse quando uma determinada sociedade participa ativamente do capital e no controle de outra ou outras sociedades, tornando-se um centro de poder importante para a tomada de decisões e os rumos das atividades 
empresarias. Nesse sentido, a doutrina moderna dispõe que:

As Holdings são sociedades não operacionais que tem seu patrimônio composto de ações de outras companhias. São constituídas ou para o exercício do poder de controle ou para a participação relevante em outras companhias, visando nesse caso, constituir a coligação. Em geral, essas sociedades de participação acionária não praticam operações comerciais, mas apenas a administração de seu patrimônio. Quando exerce o controle, a Holding tem uma relação de dominação com as suas controladas, que serão suas subsidiárias (CARVALHOSA, 2009, p. 14).

A expressão provém de um verbo da língua inglesa, "to hold", normalmente traduzido para o português como "segurar", o que denota exatamente à ideia da participação no capital das sociedades, ou ainda a noção do controle empresarial exercido pela cúpula diretiva.

A previsão legal para as Holdings aparece pela primeira vez na legislação brasileira através da Lei no 6.404, do ano de 1976, também conhecida como a Lei das Sociedades Anônimas (Lei das S.A's.) (BRASIL, 1976).

Embora a referida Lei não traga detalhadamente as classificações para essa forma de concentração de empresas, é possível notar breves aspectos para que se constitua a Holding ao ler o Art. $2^{\circ}, \S 3^{\circ}$, o qual dispõe dessa maneira: "A companhia pode ter por objeto participar de outras sociedades; ainda que não prevista no estatuto, a participação é facultada como meio de realizar o objeto social, ou para beneficiar-se de incentivos fiscais".

No que diz respeito, ainda, à visão norte-americana de Holdings, bem como à sua diferenciação com outra forma de concentração, as Joint 
ventures, e abordando a realidade jurídica brasileira, tem-se que:

Holding é o termo qualificativo que no Direito Privado Estadunidense é utilizado para identificar as empresas que se relacionam em exercício de propriedade nas participações por envolvimento direto em outras empresas e empreendimentos. Significa, em essência: participação, envolvimento, e posição diretiva. Esse termo carrega uma terminologia distintiva nos Estados Unidos da América (de onde surge) da expressão empresarial Joint Venture, que apesar de significar "empreendimento conjunto" trata apenas das associações para uma especifica conjuntura lógica, física, e restrita a propósitos determinados. Assim, em compreensão ampla, Holding é sempre interpretada como uma conjunção ampla e irrestrita de operações múltiplas e concentradas de domínio e controle sobre diversas e incontáveis ações de uma empresa, de um grupo empresarial, e de todos os empreendimentos que são derivados desta modalidade de organização societária. No Direito Societário Brasileiro, Holding é o ente societário instrumental criado exclusivamente para organizar um conjunto empresarial no que se refere aos aspectos e atividades que não estão relacionadas com o objeto jurídico de cada uma das empresas da sua composição (BARROS, 2014, p. 73).

Existem, ainda, diversas outras formas de concentração de empresas que ocorrem no contexto econômico, como fusões, acordos, incorporações, etc. Entretanto, as principais foram escolhidas para serem abordadas no presente estudo e foram explicadas acima.

\section{CONCLUSÃO}


Diante de todo o conteúdo exposto no presente estudo, é cristalina a necessidade de se analisar de forma mais concisa a realidade concorrencial no Brasil, abordando mais detalhadamente a concorrência praticável no ordenamento jurídico e especialmente na Constituição Federal, a partir da análise dos preceitos que repercutem em todas as normas infraconstitucionais, bem como tratando do mercado relevante e as estruturas de mercado de forma mais dinâmica e sem o apego à tradicionais noções econômicas que, por diversas vezes, mostram-se como um obstáculo ao avanço intelectual e estrutural no que diz respeito à economia.

As novas ideias de conceitos tradicionalmente difundidos, como nos casos de monopólios e oligopólios, precisam ainda ser moldadas de forma efetiva na doutrina e legislação brasileiras, não bastando disposições superficiais e abstratas, pois uma vez que o Direito especifica os detalhes e regra as situações econômicas, a segurança jurídica é preservada e mantida em meio às surpresas que sempre acontecem na economia.

Mostra-se interessante, também, a observação do exemplo de outros países, como os EUA e nações da Europa, visto que a análise de práticas estrangeiras pode influenciar positivamente a economia e legislação nacionais.

É indispensável, ainda, como foi abordado em toda argumentação, que haja sempre considerável atenção aos diversos tipos de atos de concentração, pois são comuns no cotidiano e precisam de maior cautela em suas previsões e sanções legais. Dado isso, é necessário enfatizar o importante trabalho do Cade, órgão de proteção da concorrência do Ministério da Justiça, que possui a incumbência de apreciar o fenômeno da concentração econômica sob uma perspectiva constitucional e atual, 
visando a proteção à superioridade do interesse público.

Assim, para que se possa visualizar o tema na prática e observar a atuação dos órgãos que fazem parte do Sistema Brasileiro de Defesa da Concorrência, um exemplo bastante recente do fenômeno concentracionista ocorreu no Brasil, que foi a aprovação da compra do Banco HSBC pelo Bradesco no mês de junho, mediante apreciação realizada pelo Tribunal do Conselho Administrativo de Defesa Econômica (AC 08700.010790/2015-41) (CADE, 2016).

Conforme a nota divulgada no site do Cade, João Paulo de Rezende, em seu voto como conselheiro relator do caso e observando o próprio mercado bancário brasileiro, sustentou que a referida aquisição "contribui para o aumento dos níveis de concentração, em especial em mercados específicos direcionados a um grande número de consumidores, como depósitos à vista (conta corrente) e crédito de livre utilização a pessoas naturais e jurídicas". O relator ainda sintetizou que existe baixo grau de rivalidade no setor bancário e essa situação não acontece somente no Brasil, mas a nível mundial.

O Bradesco, no entanto, deve atentar a algumas restrições consideradas essenciais para a validação do ato, como por exemplo, adotar medidas de estímulo à competição, manter as informações transparentes aos correntistas como forma de primazia da segurança jurídica no âmbito bancário, providenciar indicadores que assegurem a qualidade do atendimento aos clientes, além do comprometimento de não realizar fusões e aquisições, pelos próximos trinta (30) meses, de empresa do ramo financeiro e administradoras de consórcio que atuem no Brasil. As exigências para a provação do ato foram consolidadas mediante um Acordo de Conduta de Concentrações (ACC).

Assim, vê-se que o ato de concentração foi aceito devido aos 
potenciais benefícios que poderá trazer à sociedade, mesmo que haja aspectos maléficos no âmbito da concorrência no mercado. Há um respeito à workable competition, pelo que é relevante afirmar que o Brasil tem seguido aos ideais modernos que orientam a economia e a legislação, mas ainda precisa aprimorar e discutir o assunto em diversos setores.

Dessa forma, é preciso sempre levar à discussão esses aspectos da economia, falando-se sobre o poder econômico das empresas e as formas pelas quais esse poder se manifesta no meio social, afetando à população que sempre tem que lidar com os acontecimentos econômicos, seja de uma forma benéfica ou mesmo com os problemas que ocasionalmente sejam instaurados.

Ademais, uma economia respeitável e digna de admiração não é necessariamente aquela perfeita sobre a ótica estrutural do mercado, mas sim aquela que dignifica a população através de produtos e serviços de qualidade, onde a produção, venda, distribuição e consumo afetam positiva e continuamente ao público consumidor, mantendo-se o direito da concorrência e os valores constitucionais da República Federativa no Brasil.

\section{REFERÊNCIAS}

BARROS, Francisco Carlos Granjeiro. Reorganização empresarial através das estruturas societárias: aspectos gerais do desenvolvimento de empresas em Holding e sua relação com a proteção do patrimônio dos acionistas e o planejamento tributário. FABE em Revista, São Paulo, v. 4, n. 5, 2014.

BORGES, Maria Cecília Mendes et al. O Cartel na legislação antitruste, sua relação com o fenômeno concentracionista (meio ou consequência?) e seus reflexos prejudiciais aos direitos do 
consumidor. Revista de Informação Legislativa, Brasília, v. 39, n. 155, jul./set. 2002.

BRASIL. Constituição (1988). Constituição da República Federativa do Brasil de 1988. Disponível em: <www.planalto.gov.br/ccivil_03/ constituicao/constituicaocompilado.htm>. Acesso em: 17 jul. 2016.

BRASIL. Lei $\mathrm{n}^{\mathrm{o}}$ 12.529, de 30 de Novembro de 2011. Estrutura o Sistema Brasileiro de Defesa da Concorrência; dispõe sobre a prevenção e repressão às infrações contra a ordem econômica. Disponível em: <http:/www.planalto.gov.br/ccivil_03/_ato20112014/2011/Lei/L12529.htm>. Acesso em: 17 abr. 2016.

BRASIL. Lei $n^{\circ}$ 6.404, de 15 de dezembro de 1976. Dispõe sobre as Sociedades por Ações. Disponível em: <http://www.planalto.gov.br/ ccivil_03/leis/L6404consol.htm>. Acesso em: 17 abr. 2016.

BRASIL. Lei n ${ }^{\circ} 8.884$, de 11 de Junho de 1994. Transforma o Conselho Administrativo de Defesa Econômica (CADE) em Autarquia; dispõe sobre a prevenção e a repressão às infrações contra a ordem econômica e dá outras providências. Disponível em: <http:// www.planalto.gov.br/ccivil_03/leis/L8884.htm>. Acesso em: 17 abr. 2016.

BRUNA, Sérgio V. O poder econômico e a conceituação do abuso de seu exercício. São Paulo: Revista dos Tribunais, 1997. CADE - CONSELHO ADMINISTRATIVO DE DEFESA ECONÔMICA. Cade autoriza aquisição do HSBC pelo Bradesco. 2016. Disponível em: <http://www.cade.gov.br/noticias/cade-autorizaaquisicao-do-hsbc-pelo-bradesco $>$. Acesso em: 27 jun. 2016.

\section{CADE - CONSELHO ADMINISTRATIVO DE DEFESA} ECONÔMICA. Resolução nº 49, de 23 de Julho de 2008. Altera o Anexo I da Resolução 15 do CADE, de 19 de agosto de 1998 (publicada no Diário Oficial da União de 28.8.98), relativo aos atos de 
que trata o artigo 54 da Lei 8.884, de 11 de junho de 1994. Disponível em: <http:/www.cade.gov.br/assuntos/ normas-e-legislacao/resolucao/ resolucao-ndeg-49-de-23-de-julho-de-2008.pdf/view>. Acesso em: 17 jul. 2016.

CARVALHOSA, Modesto. Comentários à lei de sociedades anônimas. 3. ed. São Paulo: Saraiva, 2009.

CREMA, Renata Lais. Concentração econômica e estruturas de mercado. Monografia. 2010. (Graduação em Direito) - Universidade Federal do Paraná, Curitiba, 2010.

DAL RI JUNIOR, Arno; LIMA, Renata Albuquerque. Reflexos do conceito de Workable Competition da Escola de Harvard na Doutrina e nos Julgamentos do Cade (1988-2008). 2016.

FIGUEIREDO, Leonardo Vizeu. A questão do monopólio na Constituição da República Federativa do Brasil e o Setor Postal. Revista Eletrônica de Direito Administrativo Econômico, Salvador, n. 17, fev./mar./abr. 2009. Disponível em: $<$ http://www. direitodoestado.com/revista/redae-17-fevereiro-2009-leonardo $\% 20$ vizeu.pdf $>$. Acesso em: 17 jul. 2016.

FORGIONI, Paula A. Os fundamentos do antitruste. 2. ed. São Paulo: Revista dos Tribunais, 2005.

FORGIONI, Paula Andrea. A evolução do direito comercial brasileiro: da mercancia ao mercado. São Paulo: Revista dos Tribunais, 2009.

LIMA, Renata Albuquerque. A atuação do Estado Brasileiro e a crise empresarial na perspectiva da lei de falências e de recuperação de empresas. Rio de Janeiro: Lumen Juris, 2014. MACEDO, Rafael Rocha de. Direito da concorrência: instrumento de implementação de políticas públicas para o desenvolvimento 
econômico. 2008. Dissertação (Mestrado em Direito Político e Econômico) - Universidade Presbiteriana Mackenzie, São Paulo, 2008.

MASSO, Fabiano Del. Direito econômico esquematizado. 2. ed. São Paulo: Método, 2013.

MIRANDA, Maria Bernadete. O monopólio e o oligopólio. Revista Virtual Direito Brasil, São Paulo, v. 5, n. 2, 2011. Disponível em: $<$ http://www.direitobrasil.adv.br/arquivospdf/ revista/revistav52/ ensaios/MO.pdf>. Acesso em: 17 jul. 2016.

MIRANDA, Maria Bernadete; MALUF, Clovis Antonio. O contrato de Joint Venture como instrumento jurídico de internacionalização das empresas. Disponível em: <http://www. direitobrasil.adv.br/arquivospdf/artigos/jv.pdf $>$. Acesso em: 17 jul. 2016.

NUSDEO, Ana Maria de Oliveira. Defesa da concorrência e globalização econômica: o controle dos atos de concentração de empresas. São Paulo: Malheiros, 2002.

RUDGE, Luiz Fernando. Dicionário de termos financeiros. São Paulo: Santander Banespa, 2003.

Como citar: ROCHA, Jackson Lima; LIMA, Renata Albuquerque; CORDEIRO, Lívya Maria Vaz. Atos de concentração econômica e estruturas de mercado em uma concorrência praticável. Scientia Iuris, Londrina, v. 21, n. 2, p.64-97, jul. 2017. DOI: 10.5433/2178-8189.2017v21n1p64. ISSN: $2178-8189$.

Recebido em: 01/09/2016

Aprovado em: 16/05/2017 